\title{
A PRESENÇA DO CONCEITO \\ GÊNEROS DE DISCURSO \\ NAS REFLEXÕES DE D. MAINGUENEAU
}

\author{
Jauranice Rodrigues Cavalcanti \\ Universidade Federal do Triângulo Mineiro \\ Uberaba, Minas Gerais, Brasil
}

\begin{abstract}
Resumo: O objetivo deste artigo é analisar a presença do conceito bakhtiniano gêneros de discurso na obra de D. Maingueneau. Para isso reunimos um corpus constituído de livros do teórico francês publicados no Brasil nas últimas décadas. A análise procura responder às seguintes questões: em que medida a dimensão do estilo, tal como aparece em Gêneros de Discurso, pode ser relacionada aos conceitos de cenografia e ethos propostos pelo analista? A divisão entre gêneros conversacionais e gêneros instituídos, proposta por Maingueneau, pode ser relacionada à distinção que faz Bakhtin entre gêneros primários e secundários? Resultados apontam pontos de aproximação, mas especificidades que devem ser consideradas.
\end{abstract}

Palavras-chave: Gêneros do discurso. M. Bakhtin. D. Maingueneau.

\section{INTRODUÇÃO}

Em diferentes áreas que pesquisam a linguagem (Linguística Aplicada, Linguística Textual, Análise do Discurso etc.), o interesse pelo estudo dos gêneros de discurso explica-se pelo impacto que a leitura do texto Gêneros do Discurso de M. Bakhtin provocou nos meios acadêmicos nas três últimas décadas. Trata-se de um manuscrito inacabado, escrito nos últimos anos de vida do pensador russo (em 1952-1953, de acordo com M. Holquist), publicado em 1979 após sua morte. A primeira tradução para o

\footnotetext{
${ }^{*}$ Professor Adjunto. Pós-doutorado em Linguística.

Email: jrodriguescavalcanti@terra.com.br
} 
francês, a partir da qual é feita também a primeira tradução brasileira, data de 1983.

Nesse texto denso e instigante, Bakhtin alarga a concepção de gêneros, até então reservada a textos literários e retóricos, ao considerar que “enunciados relativamente estáveis" estão presentes em todas as esferas de atividade humana, uma vez que é por meio deles que se dá a "utilização da língua". Salienta que a diversidade dos gêneros, e a dificuldade de atribuirlhes características comuns, talvez tenha sido a causa de seu estudo ter sido relegado por tanto tempo. Para Bakhtin (2011, p. 264), pesquisas cujo objeto são enunciados concretos (escritos ou orais), que se relacionam com diferentes esferas sociais, não podem prescindir de uma concepção clara de gêneros de discurso: “[...] em qualquer corrente especial de estudo faz-se necessária uma noção precisa do enunciado em geral e das particularidades [...] dos diversos gêneros do discurso".

As considerações bakhtinianas foram, sem dúvida, incorporadas por diferentes pesquisadores, mas de acordo com os interesses de cada campo teórico. No que diz respeito à Análise do Discurso de linha francesa (AD), os trabalhos de D. Maingueneau comprovam essa influência. Já em suas primeiras pesquisas, o analista propõe a tese do primado do interdiscurso sobre o discurso, que se inscreve na perspectiva do dialogismo bakhtiniano, atribuindo a ela um quadro metodológico que permite apreender o modo como os discursos interagem. Em trabalhos posteriores, a categoria gênero de discurso ganha destaque, chegando a ocupar lugar central em suas investigações.

A fim de examinar a presença da categoria gêneros de discurso na obra do analista reunimos um corpus constituído de livros do teórico francês. São eles: Novas tendências em Análise do Discurso (1989), O contexto da obra literária (1995), Elementos de Linguística para o texto literário (1996a), Pragmática para o discurso literário (1996b), Análise de Textos de Comunicação (2001), Gênese dos Discursos (2005), Dicionário de Análise do Discurso (2004), O discurso literário (2006a), Cenas da Enunciação (2006b) e Doze Conceitos em Análise do Discurso (2010). 


\section{PRIMEIRO LIVRO}

O conceito gêneros de discurso aparece pela primeira vez na obra de D. Maingueneau em Novas tendências em Análise do Discurso, cuja primeira edição brasileira é de 1989 (a francesa é de 1987). É importante ressaltar que a primeira tradução brasileira (feita a partir do francês) de Estética da Criação Verbal, onde se encontra o texto "Gêneros do Discurso", é de 1992. No livro de Maingueneau, quando o conceito é apresentado/discutido, a referência tem por base Le principe dialogique, de Todorov, publicado em 1981 na França. Ressalte-se que, nessa mesma obra, ao apresentar o conceito heterogeneidade constitutiva, Maingueneau relaciona-o ao princípio do dialogismo bakhtiniano, mas apoia-se, do mesmo modo, no livro de Todorov.

Em sua primeira obra publicada no Brasil, Maingueneau recorre à Pragmática (usada no plural) a fim de preencher, segundo ele, uma lacuna existente na Análise do Discurso (AD) da primeira fase, qual seja, considerar o quadro da enunciação como um "conjunto de elementos moduladores" e não como "uma dimensão constitutiva do discurso". Explicam-se, assim, as metáforas de contrato, papel e cena que aparecem no conjunto de seu trabalho quando faz referência a gêneros de discurso. No entanto, o analista faz questão de ressaltar que tal "passagem" não implica assumir certos pressupostos da Pragmática, como o de um sujeito intencional estrategista, dono dos sentidos e, também, o de cena enunciativa como a "duplicação ilusória, a re-presentação de realidades, de conflitos (sociais, econômicos) dados antecipadamente" (1993, p. 33) ${ }^{1}$.

A ressalva é importante na medida em que o quadro teórico da $\mathrm{AD}$ rejeita a ideia de um sujeito livre, que faz escolhas a fim de produzir determinados efeitos em seu "auditório". A figura do sujeito individual não cabe, portanto, no quadro teórico-metodológico com o qual opera o analista, o que pode ser constatado na seguinte passagem do livro:

\footnotetext{
${ }^{1}$ As citações aqui apresentadas provêm da segunda edição brasileira.
} 
Nesta perspectiva, não se trata de examinar um corpus como se tivesse sido produzido por um determinado sujeito, mas de considerar sua enunciação como o correlato de uma certa posição sócio-histórica na qual os enunciadores se revelam substituíveis. Assim, nem os textos tomados em sua singularidade, nem os corpus tipologicamente pouco marcados dizem respeito verdadeiramente à AD (1993, p. 14).

Na primeira parte do livro, na qual figura uma seção denominada "Gêneros do discurso", Maingueneau introduz o conceito a partir do que chama de sujeito genérico que, para ele, não deve ser confundido com o sujeito linguístico tampouco com o sujeito da formação discursiva. Vejamos o que diz o analista sobre esse sujeito, recorrendo a J. M. Marandin:

Se também é necessário introduzir um sujeito "genérico", é porque, no discurso, "o indivíduo não é interpelado como sujeito, sob a forma universal do sujeito de enunciação, mas em um certo número de lugares enunciativos que fazem com que uma sequência discursiva seja uma alocução, um sermão, [...]"”. Os enunciados dependentes da $\mathrm{AD}$ se apresentam, com efeito, não apenas como fragmentos de língua natural desta ou daquela formação discursiva, mas também como amostras de um certo gênero de discurso. (grifos do autor, 1993, p. 34).

No trecho, o conceito formação discursiva (fd) aparece relacionado ao de gêneros: os enunciados dos quais a AD praticada por Maingueneau se ocupa relevam de formações discursivas que se materializam em diferentes gêneros do discurso. A noção de fd, dominante na década de 80 , será substituída por outros conceitos nas décadas seguintes. $\mathrm{O}$ analista, como ele próprio afirma, prefere empregá-la a discurso, a fim de evitar a polissemia desse último, que costuma ser usado com distintas acepções. Em relação ao sujeito genérico, trata-se do papel que devem assumir no gênero tanto o enunciador como o coenunciador (em uma aula, por exemplo, os papéis de professor e de alunos).

\footnotetext{
${ }^{2} \mathrm{O}$ trecho aspeado é retomado de J. M. Marandin, Problèmes d'analyse $d u$ discours, publicado na Revista Langages, $\mathrm{n}^{\circ} .62,1981$.
} 
Ainda nesse primeiro livro, o analista tece considerações interessantes a respeito dos gêneros. Afirma que a noção é de difícil manejo, uma vez que frequentemente os gêneros encaixam-se uns nos outros. O exemplo dado é o gênero carta de leitor, que sofre influência de um outro nível, a rubrica "correspondência de leitores", que Maingueneau considera como um gênero jornalístico. Sem dúvida, há relação entre os dois "níveis", as cartas são selecionadas, suprimidas etc. pela instância responsável por sua publicação, mas classificar essa instância como um gênero jornalístico não nos parece hoje adequado.

Maingueneau afirma que a lista de gêneros é, por definição, indeterminada uma vez que eles variam de acordo com os lugares, a época e as coerções próprias de cada um. Para ele, caberia ao analista do discurso questionar-se sobre a maneira de conhecer as coerções dos gêneros, passando

de uma concepção do gênero como conjunto de características formais, de procedimentos, a uma concepção "institucional" [...]. Isso não significa, evidentemente, que o aspecto formal seja secundário, mas apenas que é preciso articular o "como dizer" ao conjunto de fatores do ritual enunciativo (1993, p. 35-36).

A ideia de que a ênfase deve recair nos aspectos institucionais dos gêneros, e não se restringir a seus aspectos formais, é recorrente nos livros analisados, podendo ser considerada uma marca da abordagem de Maingueneau. A opção metodológica evita o risco, apontado por Bakhtin em Gêneros do Discurso, de os estudos dos diversos gêneros redundarem em formalismo, deformando a historicidade da investigação.

Diz o analista que, como todo ato de fala elementar (prometer, convidar etc.), um gênero de discurso implica condições de ordem diferentes (a que vai chamar em trabalhos seguintes de "condições de êxito"). Em Novas Tendências apresenta duas dessas condições (a comunicacional e a ligada ao enunciador genérico), que serão ampliadas e enriquecidas em momentos posteriores (sobretudo no livro Análise de Textos de Comunicação). 
Ainda em relação às coerções genéricas, Maingueneau afirma que "a explicitação das condições genéricas, de suas cenografias não representa uma finalidade para a AD" (1993, p. 37), mas sim analisar aspectos referentes à formação discursiva a ser estudada. Dessa forma,

ao considerar, por exemplo, manifestos surrealistas, sua intenção [do analista] não será a de examiná-los como amostras do gênero "manifesto", mas, antes, para compreender como o discurso surrealista investe as regras próprias desse gênero (1993, p. 37).

Assim, para Maingueneau, ocupar-se de formações discursivas investidas em diferentes gêneros significa "estabelecer a hipótese segundo a qual recorrer, preferentemente, a estes gêneros e não a outros, é tão constitutivo da forma discursiva quanto o "conteúdo"” (1993, p. 38). Tratase de defender a ideia, e encaminhar a análise nesse sentido, de que todas as dimensões dos discursos, incluindo a seleção e organização dos gêneros nos quais os posicionamentos se materializam, são regidas por regras próprias, por uma semântica global que os explica.

Em várias passagens de Gêneros do Discurso Bakhtin ressalta a relativa estabilidade dos gêneros, isto é, a transmutação por que passam devido a fatores como mudanças históricas, na vida social, nas condições e finalidades dos diferentes campos de atividade humana (esferas sociais). Além disso, destaca que, a depender do gênero, o estilo será mais ou menos refratário a manifestações individuais. Podemos ver semelhanças entre os exemplos oferecidos em Novas Tendências na seção dedicada aos gêneros do discurso e as observações de Bakhtin acerca de variações de estilo. Observemos o seguinte exemplo:

Imaginemos, agora, que um chefe de estado se dirija, durante uma viagem oficial, a uma multidão concentrada diante da tribuna. Antes mesmo que ele comece a enunciar, um certo número de coerções genéricas distribuem os lugares, circunscrevem os temas abordáveis etc. Mas, em função da formação discursiva na qual se inscreve, o enunciador poderá jogar com essas coerções ou, pelo menos, realizar escolhas significativas entre as múltiplas possibilidades que se lhe oferecem. Frustrando expectativas, poderá fingir, por exemplo, que 
desconhece a cenografia em que se encontra efetivamente implicado e realizar uma alocução familiar, evocar lembranças pessoais, falar de detalhes da vida cotidiana etc. (1993, p. 39-40).

Em trabalhos posteriores de Maingueneau, o espaço para o "jogo" com as coerções continua vinculado aos discursos, mas o analista o relaciona, também, à finalidade dos gêneros nos quais os textos são produzidos. Assim, vai apontar gêneros mais ou menos propensos a variações de cenografia, conceito que, como veremos adiante, aproxima-se da noção de estilo bakhtiniano.

\section{PUBLICAÇÕES DA DÉCADA DE 90}

O que podemos dizer sobre mudanças ocorridas em relação à apropriação do conceito gêneros de discurso em trabalhos subsequentes a Novas Tendências? Na década de 90 são traduzidos três trabalhos do analista: Elementos de Linguística para o texto literário, Pragmática para o discurso literário e $O$ contexto da obra literária, que será revisto/ampliado em $O$ discurso literário, traduzido em 2006. Os títulos mostram que o interesse do analista recai sobre enunciações literárias, campo que, segundo ele, não costuma despertar o interesse de analistas do discurso.

Em Elementos de Linguística, a noção de gêneros, sem referência a M. Bakhtin, aparece quando o analista discorre sobre "noções de gramática de texto". A tipologia apresentada nesse livro reaparece em trabalhos posteriores, sobretudo a categoria tipos de discurso, que "define para uma dada época um certo número de setores de atividade discursiva, prescrevendo ao leitor o tipo de comportamento que ele deve manter com o texto" (1996a, p. 159). Como é possível observar a noção remete a de campo/esferas sociais ${ }^{3}$ de que fala Bakhtin em Gêneros do Discurso.

Ao abordar a categoria de gêneros, Maingueneau volta a ressaltar que eles só podem ser definidos se colocados em relação a seus contextos

\footnotetext{
${ }^{3} \mathrm{Na}$ tradução do francês, esferas sociais; na de Paulo Bezerra, direto do russo, campos da atividade humana.
} 
sócio-históricos. Percebemos aqui, mais uma vez, a ênfase que o analista confere aos aspectos "extralinguísticos", o que diferencia seu trabalho daqueles que priorizam o estudo dos gêneros levando em conta, sobretudo, suas características formais.

Em relação ao livro Pragmática para o discurso literário, consideramos importante destacar a ênfase conferida ao outro (a que Maingueneau se refere como coenunciador) na construção do enunciado, o que remete a reflexões de Bakhtin acerca do papel constitutivo do ouvinte/leitor na dimensão de estilo dos gêneros. $\mathrm{O}$ analista sustenta a ideia citando Todorov que, por sua vez, refere-se a M. Bakhtin. Vejamos o fragmento:

Qualquer enunciado é concebido em função de um ouvinte, isto é, de sua compreensão e de sua resposta - não a sua resposta imediata, é claro, pois não se deve interromper um orador ou um conferencista com observações pessoais; mas também em função de sua concordância, de seu desacordo ou, em outras palavras, da percepção avaliativa do ouvinte [...]. Sabemos doravante que qualquer discurso é um discurso dialógico, orientado para alguém que seja capaz de compreendê-lo e a ele dar uma resposta, real ou virtual (1996b, p. 22, grifos do autor).

É no livro $O$ contexto da obra literária que aparece a primeira referência ao texto Gêneros de discurso de M. Bakhtin. Trata-se da seguinte citação:

Aprendemos a moldar nossa palavra nas formas do gênero e, ouvindo a palavra de outro, sabemos de imediato, desde as primeiras palavras, pressentir seu gênero, adivinhar seu volume, a estrutura composicional dada, prever seu final, em outras palavras, desde o início, somos sensíveis ao todo discursivo [...]. Se os gêneros do discurso não existissem, se não os dominássemos, se precisássemos criá-los pela primeira vez no processo da palavra, se precisássemos construir cada um de nossos enunciados, o intercâmbio verbal seria impossível (1995, p. 65). 
A mesma citação será reapresentada em trabalhos posteriores, por exemplo, em Análise de Textos de Comunicação, para que Maingueneau defenda a ideia de que o domínio de um bom repertório de gêneros de discurso representa "um fator de considerável economia cognitiva".

A questão dos gêneros de discurso é discutida no terceiro capítulo de O contexto, intitulado "Gêneros e posicionamento". Nele, Maingueneau discorre sobre a relação entre diferentes gêneros e o posicionamento do escritor na esfera literária. Nas palavras do analista:

Existe de fato uma "esfera" onde estão contidas todas as obras cujo vestígio foi conservado, uma biblioteca imaginária da qual uma pequena parte é acessível a partir de um momento e de um lugar determinados. Posicionar-se é colocar em relação um certo percurso dessa esfera com o lugar que, por sua obra, o autor se confere no campo. Escrevendo "baladas", Victor Hugo volta, para além do classicismo, a um gênero medieval, traça como que um percurso na esfera literária, afirmando-se como "romântico" (1995, p. 68-69).

A noção de posicionamento é recorrente nos últimos trabalhos do analista. Em Gênese dos Discursos, na apresentação da tradução brasileira, publicada em 2005, Maingueneau considera o conceito equivalente a formação discursiva. Em outras obras, vai diferenciá-lo de posição, que remete aos trabalhos de Pêcheux (noção inscrita no espaço das lutas sociais), ressaltando que deve ser especificada cuidadosamente em função dos tipos de discurso concernidos. No caso dos discursos religiosos, filosóficos ou literários, os posicionamentos costumam corresponder a escolas ou movimentos, o que não ocorre com outros tipos de discurso (jornalístico, publicitário, etc.).

Como defendera em Novas Tendências, os discursos (aqui os posicionamentos) se manifestam na escolha de um gênero ou de outro, na forma como organizam os gêneros selecionados. É o que mostra na pesquisa empreendida no campo religioso apresentada no Gênese: o discurso jansenista privilegia aforismas; o discurso humanista devoto, textos longos produzidos no gênero carta. 


\section{OUTRAS PUBLICAÇÕES}

Na década seguinte, são publicados quatro livros de Maingueneau: Análise de Textos de Comunicação (2001), Dicionário de Análise do Discurso (2004), em coautoria com P. Charaudeau, Gênese dos Discursos (2005) e O Discurso Literário (2006a).

Em Análise de Textos de Comunicação, ao discorrer sobre o processo de leitura, Maingueneau aponta um certo número de competências nele envolvidas, dentre elas a competência genérica, sobre a qual afirma:

Mesmo não dominando certos gêneros, somos geralmente capazes de identificá-los e de ter um comportamento adequado em relação a eles. Cada enunciado possui um certo estatuto genérico, e é baseando-nos nesse estatuto que com ele lidamos: é a partir do momento que identificamos um enunciado como um cartaz publicitário, um sermão, um curso de línguas etc., que podemos adotar em relação a ele a atitude que convém. Sentimo-nos no direito de não ler e de jogar fora um papel identificado como folheto publicitário, mas guardamos um atestado médico a ser entregue a nosso chefe (2001, p. 44).

Como podemos observar, a elaboração do conceito competência genérica toma por base as considerações do pensador russo sobre o conhecimento dos falantes a respeito dos gêneros de discurso, conhecimento este que não resulta de um ensino formal: "em termos práticos, nós os empregamos de forma segura e habilidosa, mas em termos teóricos podemos desconhecer inteiramente a sua existência" (2011, p. 282).

Maingueneau aborda um aspecto que também é discutido pelo pensador russo, a saber, o da variação da competência genérica de acordo com os sujeitos envolvidos na interação verbal. Para o analista

A maior parte dos membros de uma sociedade é capaz de produzir enunciados no âmbito de um certo número de gêneros de discurso: trocar algumas palavras com algum desconhecido na rua, escrever um cartão-postal para amigos, comprar uma passagem de trem numa bilheteria etc. Mas nem todo mundo sabe redigir uma dissertação 
filosófica, uma defesa a ser apresentada junto a uma jurisdição administrativa ou uma moção num congresso sindical (2001, p. 44, grifo do autor).

Em Gêneros do discurso, as reflexões de Bakhtin voltam-se para usuários da língua que, mesmo dominando gêneros de diferentes esferas da comunicação cultural, "cala(m) ou intervém de forma muito desajeitada em uma conversa mundana" (2011, p. 285).

Ainda em relação ao livro Análise de Textos de Comunicação, é importante destacar os capítulos voltados ao estudo dos gêneros de discurso. No de número 5, que trata do conceito, o analista apresenta tipologias que podem servir de parâmetro para a classificação de diferentes gêneros. Aquela que tem por base a situação de comunicação, com a qual trabalha Maingueneau, considera o caráter sócio-histórico dos gêneros. No Dicionário, verbete gêneros do discurso, essa tipologia é remetida à definição dada ao conceito por Bakhtin. Vejamos:

Para Bakhtin (1984:267), por exemplo, os gêneros dependem da "natureza comunicacional" da troca verbal, o que lhe permite distinguir duas grandes categorias de base: produções "naturais", espontâneas, pertencentes aos "gêneros primários" (aqueles da vida cotidiana), e produções "construídas", institucionalizadas, pertencentes aos "gêneros secundários" (aquelas produções elaboradas, literárias, científicas etc.) que derivariam dos primários (2008, p. 250-251).

Ainda em relação a tipologias, Maingueneau propõe uma distinção entre gêneros conversacionais e gêneros instituídos que se aproxima daquela proposta por Bakhtin entre gêneros primários e secundários. Nas palavras do pensador russo

Os gêneros discursivos secundários (complexos - romances, dramas, pesquisas científicas de toda espécie, os grandes gêneros publicísticos etc.) surgem nas condições de um convívio cultural mais complexo e relativamente muito desenvolvido e organizado

\footnotetext{
${ }^{4}$ As citações aqui apresentadas são da segunda edição, publicada em 2008.
} 
(predominantemente o escrito) - artístico, sociopolítico etc. No processo de sua formação eles incorporam e reelaboram diversos gêneros primários (simples), que se formaram nas condições da comunicação discursiva imediata (2011, p. 263).

Para Maingueneau, os gêneros conversacionais caracterizam-se por não ter uma ligação forte com lugares institucionais, papéis ou roteiros estáveis, sendo sua composição e temática bastante instáveis: são os parceiros que ajustam e negociam a interação enquanto essa ocorre. Os gêneros instituídos, ao contrário, estabelecem a priori papéis para seus participantes que, no geral, permanecem constantes ao longo da interação.

Em $O$ Discurso Literário, afirma que "os parâmetros que os constituem resultam na verdade da estabilização de coerções ligadas a uma atividade verbal desenvolvida numa situação social determinada" (2006a, p. 239) e que é possível, tomando por base esses gêneros, desenvolver uma escala na qual aparecem de um lado aqueles com uma margem mínima de variação (completamente ritualizados) e de outro os gêneros que "deixam grande parte sua ao sabor das variações pessoais" (2006a, p. 239).

Ainda no capítulo cinco de Análise de Textos de Comunicação, o conceito gênero de discurso é relacionado ao de cena de enunciação. Esse último já fora mencionado em Novas Tendências, mas sem o tratamento que recebe nos livros posteriores. Maingueneau propõe organizar a cena de enunciação em três dimensões, a saber, cena englobante, cena genérica e cenografia. A cena englobante corresponde ao tipo de discurso a que pertence o texto, a seu "estatuto pragmático", o que significa dizer a seu modo de funcionamento social. Esse estatuto define o modo de o texto interpelar o leitor.

No entanto, a cena englobante não é suficiente para especificar as atividades verbais nas quais se envolvem os sujeitos já que esses não se defrontam com um religioso, político ou publicitário não especificados, mas com cenas genéricas, isto é, com gêneros de discurso particulares, que implicam determinadas condições/circunstâncias de enunciação: quais são os participantes, o lugar e o momento necessários para realizar esse gênero? Quais os circuitos pelos quais ele passa? Que normas presidem seu consumo? 
As duas cenas, a englobante e a genérica, definem o espaço estável no interior do qual os enunciados ganham sentido. Em muitos casos são essas duas dimensões que compõem a cena de enunciação. Eventualmente, quando não há imposição de uma única forma composicional, outra cena pode intervir, aquela que Maingueneau chama de cenografia, que não é imposta pelo tipo ou pelo gênero do discurso, mas pelo próprio discurso.

Para exemplificar sua teoria, Maingueneau recorre à "Carta" escrita por François Mitterrand quando de sua campanha presidencial em 1988. A cena englobante da "Carta" é a do discurso político. De um ponto de vista genérico, trata-se de uma publicação por meio da qual um candidato apresenta seu programa a eleitores. No entanto, o texto não se apresenta como um programa, mas sim como uma correspondência particular, que coloca em contato dois indivíduos que mantêm uma relação pessoal. A cena epistolar não seria, assim, uma cena genérica, mas uma cenografia construída pelo texto.

Em Análise de Textos de Comunicação, e nos livros seguintes, Maingueneau distribui os diferentes gêneros em uma escala levando em conta se há ou não variação nas cenografias genéricas. Nela aparece

de um lado, os gêneros pouco numerosos, que se limitam ao cumprimento de sua cena genérica, não sendo suscetiveis de adotar cenografias variadas (cf. a lista telefônica, as receitas médicas etc.); de outro, os gêneros que, por natureza, exigem a escolha de uma cenografia: é o caso dos gêneros publicitários, literários, filosóficos etc. Há publicidades que apresentam cenografias de conversas, outras, de discurso científico etc. (grifo do autor, 2001, p. 89).

Entendemos que a noção de cenografia pode ser aproximada da dimensão do estilo tal como aparece nas reflexões de Bakhtin. Na definição dada a gêneros de discurso pelo pensador russo, o estilo - a seleção dos recursos lexicais, fraseológicos e gramaticais da língua - figura como um de seus componentes constitutivos, ao lado do conteúdo temático e da construção composicional.

No entanto, Bakhtin ressalta que nem todos os gêneros são permeáveis a manifestações de estilo individual; há aqueles que se caracterizam por um estilo objetivo neutro, "que requerem uma forma padronizada, por 
exemplo, em muitas modalidades de documentos oficiais, de ordens militares, nos sinais verbalizados da produção etc." (2011, p. 265).

Dessa forma, ao lado do estilo típico dos gêneros, pode-se manifestar um estilo individual, que decorre de um trabalho com os recursos expressivos. Pensando assim, é possível relacionar a consideração do analista sobre o caráter maleável dos gêneros situados na ponta da escala à afirmação de Bakhtin a respeito de certos gêneros abrirem espaço para um estilo individual. Além disso, não podemos esquecer o papel relevante atribuído por Bakhtin ao leitor/ouvinte na construção dos enunciados, na seleção do estilo. Em suas palavras

A quem se destina o enunciado, como o falante (ou o que escreve) percebe e representa para si os destinatários, qual é a força e a influência deles no enunciado - disto dependem tanto a composição quanto, particularmente, o estilo do enunciado (2011, p. 301).

A figura do leitor, seu papel na construção de diferentes cenografias, é ressaltada por Maingueneau em Análise de Textos de Comunicação, assim como em outros livros. O analista relaciona a variação das cenografias à finalidade dos gêneros e, por via indireta, à imagem de leitor neles embutida. Vejamos a seguinte citação:

Essa variação [das cenografias] parece estar muito ligada à finalidade dos gêneros de discurso. A lista telefônica, que não fornece uma cenografia, é um gênero puramente utilitário. Em compensação, o discurso publicitário ou o discurso político mobilizam cenografias variadas na medida em que, para persuadir seu co-enunciador, devem captar seu imaginário e atribuir-lhe uma identidade, por meio de uma cena de fala valorizada (2001, p. 90).

Pelo que verificamos, a noção de cenografia proposta por Maingueneau pode ser tomada como uma reelaboração do conceito bakhtiniano de estilo. Outro conceito que merece destaque é o de ethos discursivo, com o qual opera o analista. Na seção seguinte discutiremos a pertinência de aproximá-lo da noção de tom e entonação expressiva presentes nas reflexões de Bakhtin em Gêneros do Discurso. 


\section{ARTIGOS REUNIDOS EM LIVROS}

Nesta seção, discutiremos dois livros de Maingueneau, Cenas da Enunciação (2006b) e Doze Conceitos em Análise do Discurso (2010), que apresentam artigos do analista reunidos especialmente para as edições brasileiras. A leitura dos textos permite afirmar que o conceito gênero de discurso ganha destaque em sua obra, tornando-se categoria de análise indispensável.

$\mathrm{O}$ primeiro livro tem por fio condutor a noção de cena de enunciação, que Maingueneau vai relacionar a ethos discursivo, conceito que figura já em seu primeiro livro publicado no Brasil. Como ele próprio afirma, é uma reelaboração do conceito de ethos presente na Retórica de Aristóteles. Em suas palavras

Enquanto a Retórica ligou estreitamente o ethos à oralidade, ao invés de reservá-lo à eloquência judiciária ou mesmo à oralidade, pode-se propor que qualquer texto escrito, mesmo se ele o nega, tem uma vocalidade específica que permite relacioná-la a uma caracterização do corpo do enunciador (e não, bem entendido, ao corpo do locutor extra-discursivo), a um fiador que, por meio de seu tom, atesta o que é dito (o termo "tom" tem a vantagem de valer tanto para o escrito quanto para o oral) (grifos do autor, 2006b, p. 61).

Maingueneau considera o ethos parte integrante da cenografia (do estilo nos termos bakhtinianos): "por meio do ethos, o destinatário está, de fato, convocado a um lugar, inscrito na cena de enunciação que o texto implica" (2006b, p. 67). A noção pode ser aproximada do conceito entonação expressiva de Bakhtin na medida em que as considerações do analista sobre o tom em que enunciam os sujeitos remetem a passagens de Gêneros do Discurso, nas quais o teórico russo reflete a respeito da entonação expressiva, traço que considera constitutivo do enunciado.

Para Bakhtin, um dos meios de expressar a atitude valorativa do falante diante do objeto de sua fala é a entonação expressiva que "soa nitidamente na execução oral". Afirma também que o elemento expressivo tem significado e grau variado de força nos diferentes campos da comunicação discursiva, mas que esse elemento existe em toda parte: um enunciado absolutamente neutro é impossível, afirmação que remete ao princípio dialógico da linguagem. Vejamos a seguinte passagem: 
muito amiúde a expressão do nosso enunciado é determinada não só - e vez por outra não tanto - pelo conteúdo semântico-objetal desse enunciado mas também pelos enunciados do outro sobre o mesmo tema, aos quais respondemos, com os quais polemizamos; através deles se determina também o destaque dado a determinados elementos, as repetições e a escolha de expressões mais duras (ou, ao contrário, mais brandas); determina-se também o tom (2011, p. 297).

Dessa forma, Bakhtin destaca o papel de outros enunciados (outras vozes) na constituição dos enunciados do falante, as influências dos campos de atividade humana na seleção e constituição dos diferentes gêneros do discurso, influências que se materializam, inclusive, no tom presente nos gêneros. Tais considerações nos permitem inferir que para o teórico russo o falante sofre coerções quando da seleção e elaboração dos enunciados, ou seja, não se trata de escolhas idiossincráticas e individuais.

Maingueneau faz questão de ressaltar que, em uma perspectiva de Análise do Discurso, não se deve considerar o ethos (como o faz a Retórica) um meio de persuasão. De fato, para haver coerência com a linha teórica a que se filia, a noção de ethos proposta pelo analista não poderia fundamentar-se em uma concepção de sujeito estrategista. Assim, como uma das dimensões da discursividade, o ethos é imposto ao sujeito pela formação discursiva (posicionamento) a que este adere.

Levando em conta que as reflexões de Bakhtin sobre entonação expressiva pressupõem um sujeito (falante, como aparece na tradução de Paulo Bezerra) suscetível a influências histórico-sociais, sujeito que não goza de total liberdade, as noções de ethos discursivo e entonação expressiva são compatíveis. No entanto, não podemos menosprezar as especificidades dos conceitos que, nesse caso, podem ser explicadas pelo grau de influência que cada autor atribui ao falante/sujeito na constituição dos enunciados que produz, incluindo seu tom.

No que diz respeito aos trabalhos de Maingueneau, o sujeito é pensado em relação a papéis assumidos por ele nos diferentes gêneros do discurso. Não há discussão sobre a presença de traços de individualidade nos gêneros, já que esse não é o interesse do analista. $\mathrm{O}$ mesmo não se pode dizer das reflexões de Bakhtin: o teórico não descarta a "experiência discursiva individual" do falante na construção dos gêneros. 
Já o livro Doze Conceitos em Análise do Discurso é uma coletânea de artigos organizados em torno de conceitos (recentes ou não) que figuram no quadro teórico-metodológico do analista. Dentre os recentes, destacamos o de hipergênero, discutido em "Hipergênero, Gênero e Internet”.

Trata-se de um conceito presente em $O$ Discurso Literário, mas que aqui aparece para dar conta de novas formas de textualidade, como as que se materializam em gêneros que circulam e são produzidos na internet. Para Maingueneau, o blog não pode ser considerado um gênero, mas sim "uma espécie de hipergênero típico, cujas propriedades comunicativas são mínimas: alguém (com um nome próprio) fala sobre si mesmo (a) para alguém que esteja visitando seu website" (2010, p. 131).

Dessa forma, o traço que caracteriza os hipergêneros seria a ausência de coerções sócio-históricas, eles apenas enquadrariam uma larga faixa de textos, podendo ser usados por longos períodos e em muitos países (diálogos, cartas e diários são exemplos dados pelo analista).

A concepção clássica de gênero, de acordo com o analista, foi estruturada de acordo com o suporte e a hierarquia dos componentes da cena de enunciação (cena englobante, cena genérica e cenografia), situação modificada com o aparecimento de gêneros presentes na WEB. Para Maingueneau podem-se salientar dois movimentos convergentes, quais sejam, as coerções genéricas estão se tornando mais fracas e a cenografia assumindo papel central. No caso do blog, o mais importante é criar cenografias adequadas ao suporte material, criação que envolve a escolha das cores, do tipo da fonte, das imagens etc. que serão usadas para desenhálo.

Vê-se que a atribuição de um papel central à cenografia significa conferir maior espaço ao estilo individual, o que significa considerar os gêneros presentes na WEB permeáveis a um trabalho com a "forma" que, em se tratando de hipergêneros, envolve também a dimensão icônica dos textos.

É importante destacar que a elaboração do conceito de hipergênero se dá no interior de um quadro teórico sustentado pela concepção bakhtiniana de gêneros do discurso, o que é afirmado pelo próprio Maingueneau. Trata-se, assim, de uma reelaboração, uma tentativa de "superação" do conceito, na medida em que sua atual aplicação exige 
modificações. Nesse sentido, e pensando em sua obra como um todo, o teórico francês mostra a capacidade de "pôr para funcionar" conceitos e categorias (mesmo que provenientes de quadros teóricos distintos) a fim de apreender e explicar de forma produtiva os corpora a que se propõe analisar.

\section{CONSIDERAÇÕES FINAIS}

Neste artigo apresentamos um levantamento da presença do conceito gêneros do discurso na obra de D. Maingueneau, levando em conta os livros do analista publicados no Brasil. Vimos que a noção de gêneros aparece já em seu primeiro trabalho, antes mesmo que a tradução brasileira do texto bakhtiniano "Gêneros do Discurso", presente em Estética da Criação Verbal, fosse aqui publicada.

A leitura dos textos do analista mostrou a recorrência do conceito: em todos os livros figuram seções, capítulos ou artigos voltados à análise do fenômeno. A abordagem privilegia os aspectos "institucionais" dos gêneros, o que não significa dizer que Maingueneau não leve em conta a superfície discursiva dos textos produzidos nos diversos gêneros que analisa em sua obra (jornalísticos, literários, religiosos, publicitários, políticos etc.). Em outras palavras: os gêneros são analisados sempre tendo por objeto o discurso que neles se materializa, os posicionamentos que permitem sua seleção e construção.

No que diz respeito à aproximação dos conceitos cunhados por Maingueneau e a noção bakhtiniana de gêneros, constatamos afinidades, sobretudo na divisão entre gêneros conversacionais e instituídos, que remete à distinção entre gêneros primários e secundários feita pelo teórico russo. A noção de competência genérica, por seu turno, é elaborada levando em conta as reflexões de Bakhtin a respeito do conhecimento (muitas vezes inconsciente) de que dispõem os falantes sobre os gêneros de discurso.

Em relação ao conceito cenografia, observamos que é convergente com a noção bakhtiniana de estilo. Trata-se de um dos "planos" da cena de enunciação, presente em determinados gêneros, em especial naqueles em que o coenunciador desempenha um papel crucial. Ao afirmar que nem todos os gêneros permitem a seleção/construção de cenografias variadas, Maingueneau acolhe a distinção apontada por Bakhtin entre gêneros 
padronizados (em que o elemento criativo está ausente) e gêneros mais livres. Esses últimos permitem, nos limites de sua relativa estabilidade, manifestações da "vontade discursiva do falante". No entanto, como ressaltamos, não se podem desconsiderar especificidades decorrentes do quadro teórico no interior do qual cada autor elabora seus conceitos.

Já o conceito de ethos guarda semelhanças com a noção de tom e tonalidade expressiva presente em Generos do Discurso. Para Bakhtin os gêneros incluem tonalidades expressivas que revelam a atitude valorativa do falante, tonalidades previstas pelo próprio estilo dos gêneros. Maingueneau, como vimos, relaciona o ethos à cenografia, afirmando que não se trata de uma "estratégia" de que o enunciador lança mão, mas de uma das dimensões do discurso (posicionamento) a que esse sujeito adere.

Por último, o conceito de hipergênero, elaborado tendo por fundamento o de gêneros de discurso, comprova a influência das reflexões bakhtinianas no trabalho de Maingueneau. Entendemos que sua elaboração atesta a habilidade do analista em mobilizar conceitos anteriormente produzidos e "fazê-los avançar", sem esquecer as especificidades do quadro teórico-metodológico da $\mathrm{AD}$ por ele praticada.

\section{REFERÊNCIAS}

BAKHTIN, M. Gêneros do Discurso. Estética da Criação Verbal. Trad. Paulo Bezerra. 6. ed. São Paulo: Martins Fontes, 2011. p. 261-306.

MAINGUENEAU, D. Novas tendências em Análise do Discurso. Trad. Freda Indursky. 2.ed. Campinas: Pontes, 1993.

. O contexto da obra literária. Trad. Marina Appenzeller. São Paulo:

Martins Fontes, 1995.

. Elementos de Linguística para o texto literário. Trad. Maria Augusta de Matos. São Paulo: Martins Fontes, 1996a.

. Pragmática para o discurso literário. Trad. Marina Appenzeller. São Paulo: Martins Fontes, 1996b.

. Análise de textos de comunicação. Trad. Cecília P. de Souza-e-Silva e Décio Rocha. São Paul: Cortez, 2001.

. Gênese dos discursos. Trad. Sírio Possenti. Curitiba: Criar edições, 2005.

. O discurso literário. Trad. Adail Sobral. São Paulo: Contexto, 2006a.

. Cenas da enunciação. Trad. Sírio Possenti e Cecília P. de Souza-e-Silva.

Curitiba: Criar edições, 2006b. 
; CHARAUDEAU, P. Dicionário de Análise do Discurso. Trad. Fabiana Komesu (Org.). 2. ed. São Paulo: Contexto, 2008.

. Doze conceitos em Análise do Discurso. Trad. Sírio Possenti e Cecília P. de Souza-e-Silva. São Paulo: Parábola, 2010.

\section{Recebido em: 03/10/12. Aprovado em: 29/07/13.}

Title: The incidence of discourse genre concept in D. Maingueneau's work

Author: Jauranice Rodrigues Cavalcanti

Abstract: This article discusses the incidence of discourse genre concept in D. Maingueneau's work. For this purpose, data was collected comprising his books, published in Brazil in the last decades. The analysis intends to answer the following questions: to what extent the style level, as which appears in Discourse Genres, can be related to the concepts of scenography and ethos as proposed by the analyst? Can the division between conversational genres and institutional ones, proposed by Maingueneau, be linked to that by Bakhtin between primary and secondary genres? The results show connecting points, but also that specificities should be taken into account.

Keywords: Discourse genres. M. Bakhtin. D. Maingueneau.

Título: La presencia del concepto géneros de discurso en las reflexiones de D. Maingueneau

Autora: Jauranice Rodrigues Cavalcanti

Resumen: El objetivo de este artículo es analizar la presencia del concepto bakhtiniano géneros de discurso en la obra de D. Maingueneau. Para eso reunimos un corpus constituido de libros del teórico francés publicados en Brasil en las últimas décadas. El análisis procura responder a las siguientes cuestiones: ¿en qué medida la dimensión del estilo, tal como aparece en Géneros de Discurso, puede ser relacionada a los conceptos de escenografia y ethos propuestos por el analista? La división entre géneros conversacionales y géneros instituidos, propuesta por Maingueneau, ¿puede ser relacionada a la distinción que hace Bakhtin entre géneros primarios y secundarios? Resultados destacan puntos de aproximación, más especificidades que deben ser consideradas. Palabras-clave: Géneros del discurso. M. Bakhtin. D. Maingueneau. 